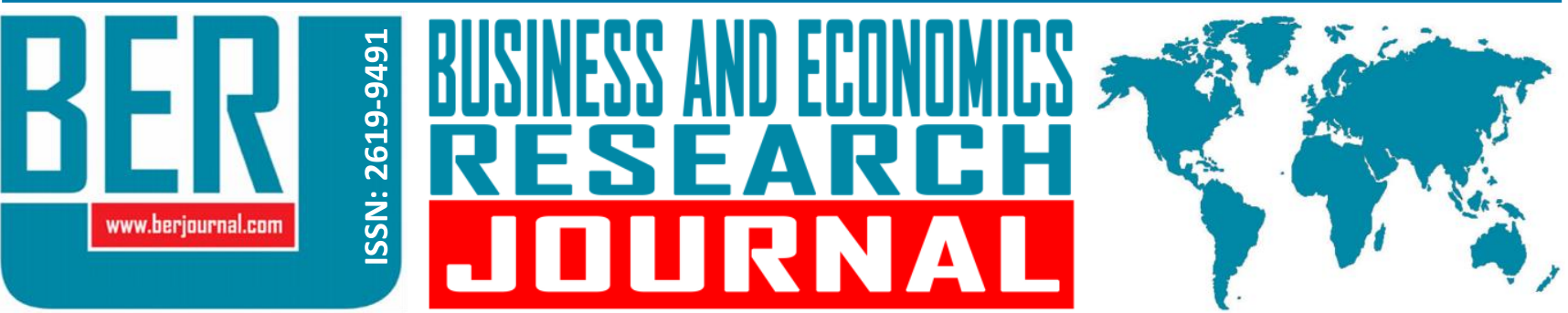 \\ Business and Economics Research Journal Vol. 12, No.1, 2021 \\ pp. $157-172$ \\ doi: $10.20409 /$ berj.2021.316
}

\section{The Assessment of The Intermediation Role of Emotional Labor Dimensions in The Relationship between Cultural Intelligence and Individual Work Performance ${ }^{1}$}

\author{
Ibrahim Yikilmaz ${ }^{\mathrm{a}}$, Deniz Devrim Tasdemir ${ }^{\mathrm{b}}$, Hulya Gunduz Cekmecelioglu
}

\begin{abstract}
Within the organization and market environment, where the number of businesses that provide services focused on a single culture is decreasing, the number of multinational companies that appeal to different customer profiles is increasing, the borders and distances between organizations are reducing, and cultural intelligence and emotional labor concepts are becoming increasingly important in terms of providing vital outputs to organizations. In this study, the data obtained from 261 participants from 50 countries serving for NATO in Afghanistan were evaluated. In the study, the relationship between cultural intelligence, emotional labor, and individual job performance, and the mediating role of emotional labor (surface, deep and genuine acting) in the relationship between cultural intelligence and job performance were examined. The results of the research show that in a multicultural work environment consisting of individuals from different countries and cultures, the cultural intelligence levels of the employees affect their emotional labor behavior and individual job performance. The results also show that the two emotional labor subdimensions (surface and genuine acting) have a partial mediating effect in the relationship between cultural intelligence and individual job performance. The study makes important contributions by addressing the exhibition of emotional labor specifically for public officials (providing security services) and by examining cultural intelligence as the premise of emotional labor and, as a consequent, job performance in an international cultural context.
\end{abstract}

\begin{abstract}
Keywords: Cultural Intelligence, Individual Job Performance, Emotional Labor, Surface and Genuine Acting
\end{abstract}

JEL: M10, M12
Received : 15 September 2020

Revised : 05 November 2020

Accepted : 30 December 2020

Type : Research

\section{Introduction}

In today's circumstances, very few businesses operate independently of the multicultural work environment (Baluku, Kikooma, Bantu, Onderi \& Otto, 2019: 6). The most important strategic advantage in the organizational and market environment characterized by such intense cultural diversity is to ensure compliance and cooperation with different values and understanding environments (Sürücü \& Sürücü, 2020: 1048). For businesses in a multicultural context, it is important to understand the individuals they serve in a cultural and emotional sense and to increase the service quality in the establishment of sustainable success (Bharwani \& Jauhari, 2013). The prerequisite for quality and sustainable service provision in public

\footnotetext{
a Res. Asst., Kocaeli Universty, Faculty of Economics and Administrative Sciences, Department of Business Administration, Kocaeli, Turkiye, ibrahimyklmz@gmail.com (ORCID ID: 0000-0002-1051-0886)

b Turkish Armed Forces, dennisdevrim@hotmail.com (ORCID ID: 0000-0001-5396-9788)

Prof., PhD., Kocaeli Universty, Faculty of Economics and Administrative Sciences, Department of Business Administration, Kocaeli, Turkiye, hulyacekmecelioglu@gmail.com (ORCID ID: 0000-0002-0123-4939)
} 
institutions within the service sector is "to work together, to cooperate and to adhere to the requirements of the task" (Guy, Newman \& Mastracci, 2014). The strategies of regulation of emotions exhibited by employees while fulfilling the requirements of the task are examined within the scope of emotional labor. In particular, employees who provide public service feel the emotional labor more intensely (Van Gelderen, 2013). Compared to other service sector employees, public servants have to wear stiff and government official masks during their duties. It is more vital for all parties to control the negative emotions of security forces within the scope of public service (Stanley \& Larsen, 2019). Although public employees display intense emotional labor, especially the security forces, it appears to be a subject of little interest in the literature (Van Gelderen, 2013). Military personnel serving beyond their own territory (such as the NATO union in Afghanistan) often carry out tasks that support the service provision of existing state organizations for the continuity of social life, ensure their security and have intensive contact with the public (NATO and Afghanistan; 2020). The Joint Mental Health Advisory Team 7 unit, which was established to examine the behavior health of military personnel working in Afghanistan, states that military personnel are struggling with many factors while performing their duties and that they are under psychological pressure, not just an armed attack (J-MHAT 7 Report, 2011). In addition, security forces are obliged to constantly review their behavior and control their emotions within the scope of the rights granted to them by law (Daus \& Brown, 2012: 309). Most of the time, they experience cognitive dissonance leading to "depersonalization" due to the effects that the results will create on the opposite side in situations that conflict with their own values and perspectives (Schaible \& Six, 2016). The emotions that the security forces feel and have to display cause them to exhibit a high level of emotional labor. In this respect, it is important to examine the premises of emotional labor to increase the quality of the service and job satisfaction while reducing the negative effect on organizational performance.

As a result of globalization and various technological advances, in multinational business environments with heterogeneous characteristics where labor, capital, and resource mobility are global, the importance given to a management approach that supports diversity is increasing (Ng \& Earley, 2006) and cultural differences are regarded as being advantageous. On the other hand, the issue of managing the differences in multicultural work environments, which is called a cultural mosaic, is also very important in terms of eliminating the problems of cultural conflict, incompatibility, and job dissatisfaction, which are thought to prevent sustainable competitive advantage and business efficiency (Jyoti \& Kour, 2015; Barakat, Lorenz, Ramsey \& Cretoiu, 2016; Sürücü \& Sürücü, 2020). In such multicultural work environments, the necessity to have employees and managers who are capable of working in and adapting to different cultures, communicating effectively and have high cultural intelligence (White, 1999; Parker, 2005; Triandis, 2006; Jyoti \& Kour, 2015: 237; Wang, 2016; Fang, Schei \& Selart, 2018) as well as high emotional labor demonstration is also increasing. Emotional labor is the display of expected behavior in accordance with the requirements of the job and the management of emotional process (Wharton \& Erickson, 1993: 458; Ashforth \& Humprey, 1993: 90; Grandey, 2000: 95). Emotion, which is the determining factor in the cause and effect relationship of emotion-emotion management, is likely to be influenced by individual differences (cultural intelligence) and cultural context (Barrera, 2010). Culture represents the values and patterns of understanding shared by different communities. Also feeling rules and strategies for emotional regulation vary across cultural context (Mesquita \& Albert, 2007). The limited number of studies examining the concept of emotional labor in a cultural context (MCance, 2010; Chuapetcharasopon, 2014; Salleh, 2014) has led us to examine the concept of cultural intelligence as one of the premises of emotional labor. Cultural intelligence (Peterson, 2004: 89), defined as the capacity to adapt to different cultural sets and behave appropriately, is considered to be effective in determining the required emotional labor strategy of the employee. Cultural intelligence plays an important role in exhibiting the behaviors required in multicultural settings (Ott \& Michailova, 2016). Cultural intelligence (CQ) increases the effectiveness of the management process of the organization as well as the ability of employees to work and manage the process effectively when they encounter a cultural experience other than their own (Ang et al., 2007: 337; Sürücü \& Sürücü, 2020: 1048). In addition, it is emphasized that cultural intelligence plays a decisive role in adapting to different organizational structures and business environments (Livermoore, 2011: 5). But despite its importance, Cultural Intelligence is a relatively new concept with limited studies (Kour \& Sharma, 2017). Besides all these, 
the existence of a large number of cultures makes communication and business challenging (Lee, 2015; O'Dowd, 2018), and this situation also increases the display of emotional labor, which is a process in which employees exhibit the types of behaviors expected by the organization. In this context, to fill an important gap in the literature, the relationships between cultural intelligence, emotional labor, and job performance of individuals working in a multicultural environment are examined in NATO union in Afghanistan. In the study, the aim is to determine the effects of cultural intelligence on emotional labor (surface, deep, and genuine acting) and individual job performance, and the mediating role of the three dimensions of emotional labor in the relationship between $C Q$ and individual job performance. First, the theoretical framework of the study was explained and the accumulated literature was summarized. Subsequently, analysis and findings were shared and recommendations were made in the conclusion part. This study is considered to have two important contributions. Firstly, this study is important in terms of considering cultural intelligence and emotional labor concerning job performance in an environment where individuals from different cultures are expected to work in harmony for a specific purpose and job. Secondly, the study makes significant contributions by addressing the emotional labor display specifically for public servants (providing security services) and by examining the premises (cultural intelligence) and consequent (job performance) of emotional labor in an intercultural context.

\section{Theoretical Framework}

\subsection{Cultural Intelligence and Emotional Labor}

The concept of emotional labor was first studied by Hochschild (1979). Emotional labor has been considered as an important concept with regard to the physical labor of individuals in the process of fulfilling their duties and it has been conceptualized as "the management of emotions through conscious and systematic efforts, together with the mimical and bodily expressions that individuals exhibit following the job requirements in the work environment" (Hochschild, 1979; Hochschild, 1983: 7). Emotional labor is defined as the management of emotions by individuals (Wharton \& Erickson, 1993: 458), effort and control in displaying expected emotions (Morris \& Feldman, 1996: 987), and the regulation and orientation of certain emotions according to organizational expectations (Ashforth \& Humprey, 1993: 90; Grandey, 2000: 95). The concept of emotional labor was initially considered as a two-dimensional structure comprised of "surface" and "deep" (Hochschild, 1983), and then the dimension of "genuine acting" was added to this structure (Ashforth \& Humphrey, 1993: 94). Accordingly, while expressing the situation in which the employee who exhibits surface acting reshapes and controls the emotional state only in a behavioral stage (such as a fake smile) without feeling real (Ashforth \& Humprey, 1993: 92); however deep acting is defined as the process of trying to experience the exhibited emotion, controlling inner thoughts and emotions, developing behavior with previous experiences and empathy (Brotheridge \& Grandey, 2002: 22; Rupp, McCance, Spencer \& Sonntag, 2008: 4). Genuine acting refers to the behavior that is exhibited spontaneously, without the need for empathy, in which the felt and expressed emotion is real and sincere, and it is defined as the nonmanipulated state of emotions (Astforth \& Humprey, 1993: 94; Prati, 2004: 64).

The global growth experienced in the service sector, creating a more intense competitive environment and the presentation of emotions that meet the expectations of the customer in this environment, becomes even more decisive in the service interaction between the employee and the customer (Chu \& Murrmann, 2006; Teng, 2019; Chi \& Grandey, 2019). While other service sector employees experience emotional labor due to their being in a more polite and supportive emotional state, public officials (officers, firemen, police, task collector, etc.) experience emotional labor more deeply. Because public officials need to be tougher than they feel while performing their duties and engage in a verbal fight (verbal judo) with the citizens, and then they have to direct their behavior according to the requirements of the mask of being a lawman offered by the state power (Guy, Newman \& Mastracci, 2014). This situation becomes an even more important issue, especially for the security forces (Stanley \& Larsen, 2019).

There are very limited studies on emotional labor in intercultural contexts (MCance, 2010; Chuapetcharasopon, 2014; Salleh, 2014). However, as Mesquita and Delvaux (2013) stated, what is known 
about emotional labor is based on Hochschild's study on North American Middle-class flight attendants in a cultural context. Culture is related to how the individuals express their emotions, and the values and perceptions in culture have a determining effect on the shaping of the behavior (Barrera, 2010). It is stated that in a different cultural context, emotional labor as emotional regulation, can be better understood in the cultural context, but the cultural context is lacking in the studies (Mesquita \& Albert, 2007). Also feeling rules and strategies for regulation vary across cultural context (Mesquita \& Albert, 2007). Emotional regulation strategies differ in two ways (re-appraisal and suppression) across cultures. "Re-appraisal" is defined as adopting different perspectives and directing feelings in the same direction as well as the appraisal. This is defined as "deep acting" in the conceptualization of Hochschild. "Suppression", which is one of the emotional regulation strategies arising from cultural differences, is related to showing the necessary emotional response. Despite the current facts, the behavioral response is regulated in the expected direction. Even though it is different from the person's feelings and behaviors, the expected behavior in suppression is presented and the emotion displayed accordingly is regulated. In the conceptualization of this Hochschild, it is defined as surface acting (Mesquita \& Delvaux, 2013). In studies on emotional labor, a "construct driven" explanation is preferred rather than "theory-driven" (Dahling \& Johnson, 2013). According to Dahling and Johnson (2013), the effect of individual differences (cultural intelligence) on emotional labor can be explained with "Trait theory". Trait theory is related to the personality trait's having a determining effect on the consistent display of some behaviors. Personality trait as the determinant of behaviors defined as "psychological qualities that contribute to an individual's enduring and distinctive patterns of feeling, thinking, and behaving" (Cervone \& Pervin, 2008) and "a generalized neuropsychic structure (peculiar to the individual), with the capacity to render many stimuli functionally equivalent, and to initiate and guide consistent (equivalent) forms of adaptive and stylistic behavior" (Allport, 1937). As stated by Dahling and Johnson (2013); employees' traits (skills and competencies) affect the regulation of their emotions and their relationships with other people. In this process, a cause and effect relationship is formed in emotional labor. $\mathrm{CQ}$ is a multidimensional trait and defined as the ability to understand and adapt to unfamiliar situations in a cultural context (Ang, Van Dyne, \& Koh, 2006; Ang et al., 2007; Van Dyne et al., 2008). At this point, individual differences (cultural intelligence, cultural context) that direct the behaviors of individuals can be among the determining premise in displaying emotional labor (Bukcner, 2012). Cultural intelligence, which has the capacity to adapt to different cultural environments and act as required, may also make it possible to display the proper behavior style (implementation of the appropriate emotional labor strategy) as required by the task (McCance, 2010). In this context, cultural intelligence, which has the ability to adapt to different cultural sets and to exhibit the proper behavior in this environment, has been examined within the scope of the study.

Cultural intelligence is defined as the ability to adapt to culture-based values and attitudes in the projects involving different individuals who interact in this different cultural structure (Peterson, 2004: 89). The concept of cultural intelligence is multidimensional and is expressed and measured by researchers in different dimensions. The concept of cultural intelligence is considered and studied as a four-dimensional structure in its most accepted form (Ang et al., 2007: 337). The first of these dimensions is the metacognitive cultural intelligence dimension, which is defined as the conscious level of cultural awareness in intercultural interaction (Ang \& Van Dyne, 2008: 5). The observation, planning, and processing of the cognitive process related to the internalization of differences between two different cultures occur under this dimension (Ang et al., 2007: 338). Cognitive cultural intelligence refers to learning the special structures belonging to other cultures, such as the attitudes, values, behavioral structures, social order, and legal structures of individuals in formal and informal relationships with other individuals who have different cultural structures. It is separated from the meta-cognitive dimension in this respect (Ang, Van Dyne \& Koh, 2006; Ang \& Van Dyne, 2008: 5). Motivational cultural intelligence dimension denotes the acceptance of the existence of different cultural structures, the tendency to act according to these structures, and to work in different cultures (Ang \& Van Dyne, 2008: 6). Behavioral cultural intelligence is defined as the ability to perform appropriate verbal and non-verbal actions during interaction (Ang \& Van Dyne, 2008: 6); it refers to the effective functioning of other dimensions and their transformation into a "concrete" behavior (Fang et al., 2018). 
In multicultural work environments, it is considered that cultural intelligence, which is defined as the individual's adaptation to the new cultural set and directing their actions according to the requirements of the culture, can be among the premises of emotional labor, which is defined as the management of emotions within the scope of the requirements of the job (Bukcner, 2012). Having examined the studies on the concepts of cultural intelligence and emotional labor, it is seen that a very limited number of studies have focused on the relationship between these two variables (McCance, 2010; Chuapetcharasopon, 2014; Salleh, 2014). McCance (2010) examined the relationship between cultural intelligence, emotional labor, and the performance of hospitality sector employees who provide intercultural services. At the hypothesis development phase of this study, it was predicted that individuals with high cultural intelligence can exhibit a more sincere and genuine attitude (deep and genuine acting strategy) towards their colleagues with different cultural values under uncertain circumstances and working conditions (Lustig \& Koester, 2006) and individuals with low cultural intelligence can exhibit more surface acting in the organizational environment. However, she concluded that while cultural intelligence (CQ) does not affect surface acting, CQ affects deep acting, and the effect of $\mathrm{CQ}$ on performance is not mediated by deep and surface acting. Following this study, Chuapetcharasopon (2014) examined the effects of $C Q$, intergroup anxiety, and intercultural service provision on surface acting on nurses in a global context. In his study, he concluded that only the metacognitive CQ dimension is indirectly related to surface acting. The behavioral CQ is directly related to surface acting. In the third study, Salleh (2014) examined the relationships between cultural intelligence, emotional labor, and job burnout. It is stated that individuals with high and low cultural intelligence levels differ in their emotional labor behavior. It is emphasized that individuals with high cultural intelligence can better manage the expectations of their customers and emotional regulation, in other words, emotional labor strategies.

\subsection{The Mediating Role of Emotional Labor on The Relationship Between Cultural Intelligence and Individual Job Performance}

When the studies involving the variables of our study are examined, it can be observed that cultural intelligence makes significant contributions to both individual and organizational levels. Also, its relationship with premises such as personality traits (Ang, Van Dyne \& Koh, 2006), cross-cultural experience and orientation (Crowne, 2008; Harrison, 2012; Li, Mobley \& Kelly, 2013; Kurpis \& Hunter, 2017; Pekerti \& Arli, 2017; Schwarzenthal, Juang, Schachner, Van de Vijver \& Handrick, 2017) and social intelligence (Depaula, Azzollini, Cosentino \& Castillo, 2016) has been studied. According to the findings in the literature, it is shown that cultural intelligence increases the job satisfaction of employees in multinational organizations with cultural diversity and reduces their anxiety levels (Bücker, Furrer, Poutsma \& Buyens, 2014; Telli \& Zehir, 2016), burnout (Tay, Westman \& Chia, 2008) and cynicism (Çalışkan, Ünal, Kalafatoğlu, Üçler \& Akün, 2015). On the other hand, it has been observed that cultural intelligence positively affects team performance (Groves \& Feyerherm, 2011) and increases both organizational commitment (Eskandarpur, Nazari, Vejdan \& Tohidi, 2013) and job performance (Rose, Ramalu, Uli \& Kumar, 2010: 76-85). Cultural intelligence is also considered as one of the essential traits for leadership, where leaders increase creativity, entrepreneurship inclination, and innovation adoption (Elenkov \& Manev, 2009; Yıldız, 2016; Xu \& Chen, 2017; Lorenz, Ramsey $\&$ Richey, 2018). It has been studied out that leaders with high cultural intelligence have a positive effect on the organizational citizenship behavior and job satisfaction of their subordinates with whom they work (Şahin, 2011: 98).

When the studies on the concept of emotional labor are examined, Emotional Labor affects job performance, the intention to quit and employees who display surface acting have low job performance (Gross, 1998; Tice \& Bratslavsky, 2000; Goodwin, Groth \& Frenkel, 2011; Beğenirbaş \& Çalışkan, 2014). Also, it is seen that the deep and genuine acting efforts of employees increase job performance (Grandey, Fisk, Mattila, Jansen \& Sideman, 2005; Goodwin et al., 2011).

In the above section, it is stated that cultural intelligence has a determining effect on emotional labor (McCance, 2010; Bukcner, 2012; Chuapetcharasopon, 2014; Salleh, 2014). Also, studies emphasize that both cultural intelligence and emotional labor are effective in individual performance (Gross, 1998; Tice \& Bratslavsky, 2000; Grandey et al., 2005; Rose et al., 2010: 76-85; Groves \& Feyerherm, 2011; Goodwin et al., 
2011; Beğenirbaş \& Çalışkan, 2014). From this point of view, it is considered that emotional labor strategies can play a mediating role in the effect of individuals with high cultural intelligence on individual job performance in a multicultural organization.

The following hypotheses have been developed to be investigated in the study within the scope of the literature reviews.

$H_{1}$ : Cultural intelligence has a significant effect on individual job performance.

$\mathrm{H}_{2}$ : Surface acting has a significant effect on individual job performance.

$H_{3}$ : Deep acting has a significant effect on individual job performance.

$\mathrm{H}_{4}$ : Genuine acting has a significant effect on individual job performance.

$H_{5}$ : $C Q$ has a significant effect on surface acting, one of the emotional labor sub-dimensions.

$H_{6}$ : $C Q$ has a significant effect on deep acting

$H_{7}$ : CQ has a significant effect on genuine acting

$H_{8}$ : Surface acting has a mediating role in the effect of cultural intelligence on individual job performance.

$H_{9}$ : Deep acting has a mediating role in the effect of cultural intelligence on individual job performance.

$H_{10}$ : Genuine acting has a mediating role in the effect of cultural intelligence on individual job performance.

\section{Methodology}

\subsection{Data and Research Method}

This study is designed as a quantitative research model. The research was conducted on the members of a public organization gathered for the offering of security and public services in a multinational environment. Data were collected from The Resolute Support Mission (NATO) military personnel positioned in Kabul. Information about the purpose of the study and how to collect data was shared with the head coordinator and unit leaders. With detailed planning, questionnaires were applied by informing the participants during the rest periods with voluntary participation. The survey study was carried out for two weeks (in March-April 2019) and was applied to the participants selected by convenience sampling method. 280 questionnaires were prepared to collect survey data. Surveys were delivered to the unit leaders, in a sealed envelope and were collected in a sealed envelope. Having examined the gathered questionnaires, 19 questionnaires that were not filled properly were not included in the study. Thus, the research was completed over 261 survey data. $62.1 \%$ of the participants were married, $79.3 \%$ were male, $36 \%$ were undergraduates, while the age group with the highest proportion of participants was 30-34 (39.5\%). It was determined that the percentage of participants who had served between 1-5 years was $72.4 \%$. The research model is shown in Figure 1.

Figure 1. Research Model

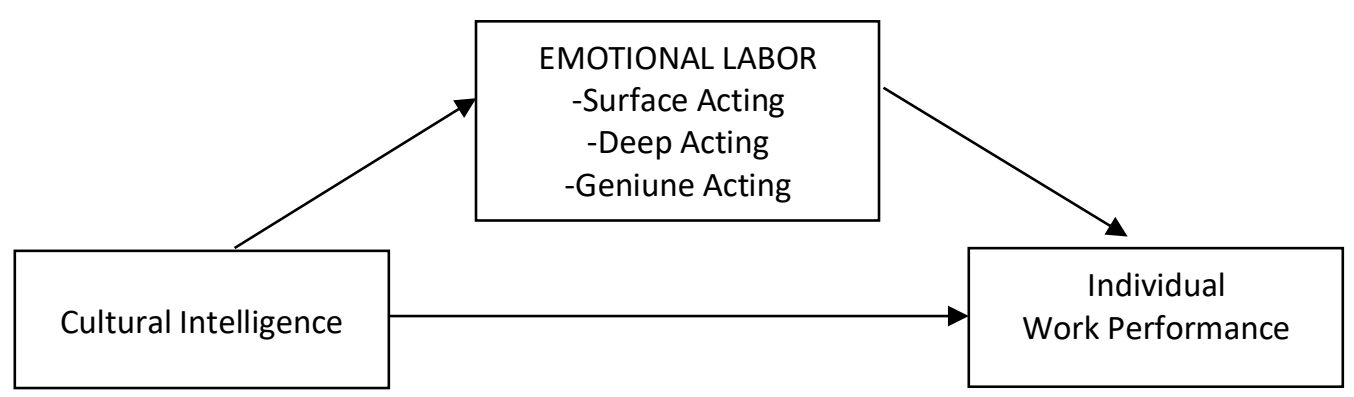


To determine the mediating role of emotional labor in the effect of cultural intelligence on job performance, the following scales were used. As an instrument for measuring Cultural Intelligence, the scale developed by Ang et al. (2007) was used, while the scale taken from Diefendorff et al. (2005) was used as emotional labor scales. To measure the individual job performance perceptions of the participants, the "Perceived Individual Work Performance Scale" developed by Singler and Pearson's (2000) from the Kirkman and Rosen (1999)'s scale was used. The data obtained as a result of the surveys were analyzed using SPSS 22.0 and Amos 20 package programs. Explanatory factor analysis (EFA) was conducted to test the structural validity of the scales used in the study. According to the factor analysis results, the cultural intelligence scale with 4 factors explains $63.707 \%$ of the total variance (KMO value is 0.770 and Bartlett's test result is $p<0.001$ ), the emotional labor scale with 3 factors explains $64.575 \%$ of the total variance (KMO value is 0.824 and Bartlett's test result is $p<0.001$ ) and job performance explains $47.233 \%$ of the total variance with a single factor (KMO value is 0.691 and Bartlett's test result is $p<0.001$ ). The reliability of the scales was evaluated by determining the Cronbach's alpha internal consistency coefficients. Analyzes show that cultural intelligence (0.784), individual job performance (0.701), genuine acting (0.701), deep acting (0.856), and surface acting (0.816) scales are reliable measurement tools (Mackenzie, Podsakoff \& Podsakoff, 2011; Sürücü \& Maslakçı, 2020).

Finally, the fit indices of the research model were determined by CFA (confirmatory factor analysis) analysis. In line with the recommendations of AMOS in the CFA analysis; a modification was made between the items 1-3 and 6 - 8 belonging to "Cultural Intelligence" and items $6-7$ belonging to the "Emotional Labor". After the modifications are complete, CFA results show that the research model has good fit indices (CMIN / DF 1,689, GFI 0.918, RMSEA 0.051 CFI 0.918; S(RMR) 0.073) (Kline, 2005; Hair et al., 2014).

\subsection{Findings}

The findings based on the analysis of the relationships between the research variables are presented in Table 1.

Table 1. Mean Value, Standard Deviation and Correlation Values Regarding the Relationship Between the Research Variables

\begin{tabular}{|l|c|c|c|c|c|c|c|}
\hline Name of The Variable & Mean & Sd & $\mathbf{1}$ & $\mathbf{2}$ & $\mathbf{3}$ & $\mathbf{4}$ & $\mathbf{5}$ \\
\hline Surface Acting & 2.9381 & 0.77673 & 1 & & & & \\
\hline Deeply Acting & 3.7615 & 0.97609 & $-0.126^{*}$ & 1 & & & \\
\hline Genuine Acting & 4.1667 & 0.71656 & $-0.482^{* *}$ & $0.254^{* *}$ & 1 & & \\
\hline Individual Job Performance & 4.3400 & 0.48441 & $-0.659^{* *}$ & $0.269^{* *}$ & $0.808^{* *}$ & 1 & \\
\hline Cultural Intelligence & 3.6630 & 0.42892 & $-0.481^{* *}$ & $0.271^{* *}$ & $0.526^{* *}$ & $0.684^{* *}$ & 1 \\
\hline
\end{tabular}

*: Correlation is significant at the 0.05 level (2-tailed).

**: Correlation is significant at the 0.01 level (2-tailed).

According to the correlation analysis, there is a negative relationship between cultural intelligence and surface acting $(r=-0.481, p<0.01)$ and a positive relationship between deep acting $(r=0.271, p<0.01)$, genuine acting $(r=0.526, p<0.01)$ and individual job performance $(r=0.684, p<0.01)$. Moreover, while there is a negative relationship between individual job performance and surface acting $(r=-0.659, p<0.01)$, a positive relationship exists with deep acting $(r=0.269, p<0.01)$ and genuine acting $(r=0.808, p<0.01)$. Hair et al, (2017) states that if a correlation over 0.800 is detected among the variables, multicollinearity bias problem may occur and therefore VIF values should be checked. In this context, the VIF values of the research are between (1.102 and 1.572). These values are below the upper threshold of 5, which is accepted in the literature. These findings show that there is no multicollinearity bias problem in the study.

The Process Macro developed by Hayes (2013) was used to determine the mediating role of emotional labor in the relationship between cultural intelligence and job performance. There are several reasons for choosing The PROCESS Macro. Generally, Baron and Kenny's (1986) method is used in determining the mediation effect and the Sobel test (Pardo \& Roman, 2013) is used in determining the statistical significance of the mediation effect. It is stated that Baron and Kenny's (1986) method can work 
even if there is no statistical effect in some cases (Pardo \& Roman, 2013). Also, as Hadi, Abdullah and Sentosa (2016) stated that there are some negative aspects of the Sobel Test, which is carried out to test whether the intermediation effect is significant or not. The Sobel test is based on the assumption of normal distribution (Fritz \& MacKinnon, 2007), but the indirect effect usually shows an asymmetrical distribution (Bollen \& Stine, 1990; Hair et al., 2014). In the Sobel test, the way of (a*b) tends to have an asymmetrical distribution. In cases where the sample size is relatively small, $(a * b)$ creates an asymmetrical distribution and prevents the Sobel test's working properly (Hadi, Abdullah \& Sentosa, 2016; Özdil \& Kutlu, 2019). In addition, the p-value obtained within the scope of the formulation does not reflect the real value. In this context, bootstrapping, which is a non-parametric resampling method, is recommended (Bollen \& Stine, 1990; Shrout \& Bolger, 2002; Preacher \& Hayes, 2004, 2008; Hadi, Abdullah \& Sentosa, 2016). The Bootstrap method is not based on the assumption of normality and produces valid results, including small samples (Pardo \& Roman, 2013; Hair et al., 2014). Also, it is stated that the popularity of the procedure proposed by Baron and Kenney (1986) has decreased recently, instead of a method focusing on the parts of the model, users have turned to applications that take the established model as a holistic and lead to indirect effect and other statistics (such as process macro and SEM) (Hayes, 2017). It is also emphasized that SEM and Hayes Process Macro mostly give the same results (Hayes, 2017). Therefore, Hayes Process Macro was used because of the convenience it offers and the superiority of Baron and Kenny (1986) in the mediation analysis process.

Using the process macro, 5000 bootstrapping was performed at $95 \%$ confidence interval $(\mathrm{Cl})$ and the mediating effect of emotional labor in this relationship was tested. According to this analysis, for the mediating effect to be considered statistically significant, a zero point should not be included between the two extreme values of the confidence interval (Preacher \& Hayes, 2008; Hayes, 2013). According to the analyses made in this context, the results shown in Tables 2 and 3 have been obtained.

Table 2. Regression Results and Hypotheses

\begin{tabular}{|l|c|c|c|c|c|}
\hline & $\boldsymbol{\beta}$ & $\mathbf{T}$ & Sig. & $\begin{array}{c}\text { Hypothesis } \\
\text { No }\end{array}$ & Results \\
\hline $\begin{array}{l}\text { Cultural Intelligence - Individual Job } \\
\text { Performance }\end{array}$ & 0.2670 & 7.5650 & 0.0000 & 1 & Accepted \\
\hline $\begin{array}{l}\text { Surface Acting - Individual Job } \\
\text { Performance }\end{array}$ & -0.2720 & -8.0770 & 0.0000 & 2 & Accepted \\
\hline Deep Acting - Individual Job Performance & 0.0280 & 0.9470 & 0.3444 & 3 & Rejected \\
\hline $\begin{array}{l}\text { Genuine Acting - Individual Job } \\
\text { Performance }\end{array}$ & 0.5300 & 15.0940 & 0.0000 & 4 & Accepted \\
\hline Cultural Intelligence - Surface Acting & -0.4808 & -8.8258 & 0.0000 & 5 & Accepted \\
\hline Cultural Intelligence - Deep Acting & 0.2710 & 4.5305 & 0.0000 & 6 & Accepted \\
\hline Cultural Intelligence - Genuine Acting & 0.5262 & 9.9577 & 0.0000 & 7 & Accepted \\
\hline
\end{tabular}

While there is a negative effect between cultural intelligence and surface acting $(\beta=-0.4808, p<0.01)$, it has been observed that there is a positive effect between deep acting $(\beta=0.2710, p<0.01)$, genuine acting $(\beta=0.5262, p<0.01)$ and individual job performance $(\beta=0.2670, p<0.01)$. While surface acting $(\beta=-0.2720$, $p<0.01)$ has a negative relationship with individual job performance, genuine acting $(\beta=0.5300, p<0.01)$ has a positive effect on it. However, there was no statistically significant effect between deep acting ( $\beta=0.0280$, $p>0.01$ ) and individual job performance. 
I. Yikilmaz - D. D. Tasdemir - H. Gunduz Cekmecelioglu

Table 3. Results Regarding the Mediating Effect

\begin{tabular}{|c|c|c|c|c|c|c|}
\hline & Coeff. & SE & LLCI & ULLC & $\begin{array}{c}\text { Hypothesis } \\
\text { No }\end{array}$ & Results \\
\hline $\begin{array}{l}\text { Indirect Effect (Cultural Intelligence } \\
\rightarrow \text { Surface Acting } \rightarrow \text { Individual Job } \\
\text { Performance }\end{array}$ & 0.2335 & 0.0299 & 0.1796 & 0.2984 & 8 & $\begin{array}{c}\text { Accepted } \\
\text { (Partial } \\
\text { Mediation } \\
\text { Effect) }\end{array}$ \\
\hline $\begin{array}{l}\text { Indirect Effect (Cultural Intelligence } \\
\rightarrow \text { Deep Acting } \rightarrow \text { Individual Job } \\
\text { Performance }\end{array}$ & 0.0277 & 0.0137 & 0.0031 & 0.0571 & 9 & Rejected \\
\hline $\begin{array}{l}\text { Indirect Effect (Cultural Intelligence } \\
\rightarrow \text { Genuine Acting } \rightarrow \text { Individual Job } \\
\text { Performance }\end{array}$ & 0.3686 & 0.0479 & 0.2792 & 0.4682 & 10 & $\begin{array}{c}\text { Accepted } \\
\text { (Partial } \\
\text { Mediation } \\
\text { Effect) }\end{array}$ \\
\hline
\end{tabular}

In the analysis of the mediating effect of emotional labor on the relationship between cultural intelligence and individual job performance, the mediator variable is expected to have a significant effect between the other variables. However, since there is no statistically significant effect between deep acting and individual job performance $(\beta=0.0280, p>0.01)$, it cannot be stated that there is a mediating effect. It can be seen in Table 2 that other mediator variables (surface acting $(\beta=-0.2720, p<0.01)$ - genuine acting $(\beta=$ $0.5300, p<0.01)$ ) have the above-mentioned relationship, in accordance with this the analysis was conducted with these variables. In the relationship between $C Q$ and individual job performance, having been included surface acting $(\beta=0.2335$, standard error $(S E)=0.0299, G A=[0.1796$ and 0.2984$])$ and genuine acting $(\beta=$ $0.3686,(\mathrm{SE})=0.0479, \mathrm{GA}=[0.2792$ and 0.4682$])$ in the models separately, it was observed that the direct effect of CQ on individual job performance still continues ( $c$ ' ways are statistically significant $(p<0.05)$ ). For this reason, the continuing effect of cultural intelligence on job performance (presence of direct effect) and its statistical significance raises the question of whether there is a partial mediating effect in the examined model. Hair et al. (2017) stated that a partial mediation effect occurs when the VAF (Variance Accounted For) value is calculated to be between $(0.2-0.8)$ reference values. Within the scope of this study, VAF values were calculated as: Surface Acting (0.3042) and Genuine Acting (0.5227). When these findings are evaluated, it is determined that surface acting and genuine acting have partial mediating roles in the effect of $C Q$ on individual job performance. In this context, it is seen that hypotheses 3 and 9 are rejected and the other hypotheses are accepted.

\section{Conclusion and Discussion}

In achieving the quality of the service and high customer satisfaction in the service and the public sector, it is important to fulfill the requirements of the duty and the exhibition of the behavior that fits the expectations of the customer. Emotional labor, which is the concept of managing behaviors in accordance with the requirements of the task, as an individual differences cultural intelligence, which is the ability to develop a cultural set of action in a multicultural environments, and the effect of these concepts on job performance, which is an important issue for sustainable competitive advantage has been examined within the scope of the study. In the study, the relationships between cultural intelligence, emotional labor dimensions, and individual job performance are examined based on research conducted on the employees of a multicultural organization that works under the NATO flag for assisting the Afghan Public Organization service provision. The results obtained in the study show that it is very important for employees who operate in a heterogeneous structure to have cultural intelligence, which is defined as the capacity to understand and comprehend different cultures and to exhibit behaviors that can adapt to this process. This research, which examines the effect of cultural intelligence and emotional labor on individual job performance in the service (public) sector, not only contributes to closing the gap in the literature, but also expands the literature on cultural intelligence and emotional labor in the multicultural context. The main findings are as follows.

The results show that cultural intelligence increases individual job performance $(\beta=0.2670, p<0.01)$, which is defined as the capacity of individuals to reach and exceed goals related to their work and to fulfill 
their job requirements. The cumulative literature on $C Q$ indicated that $C Q$ affects team performance (Groves \& Feyerherm, 2011) and job performance positively (Rose et al., 2010). Besides, emotional labor dimensions affect individual job performance too. While surface acting $(\beta=-0.2720, p<0.01)$ exhibited in the work environment decreases job performance, genuine acting $(\beta=0.5300, p<0.01)$ increases it. The effect of deep acting $(\beta=0.0280, p>0.05)$ was not found to be statistically significant. In the light of the results, Surface acting, which occurs when employees do not feel the behaviors expected to be exhibited by their organization, are not successful in increasing job performance. If the behaviors of employees are sincere, those behaviors will increase the individual job performance. These results are consistent with previous studies in the literature (Richards \& Gross, 1999; Totterdell \& Holman, 2003; Grandey, 2003; Goldberg \& Grandey, 2007; McCance, 2010). These results of the study are considered to contribute to the intercultural service context on individual job performance and emotional labor.

The research results show that $C Q$ affects individuals' emotional labor behavior positively. While $C Q$ affects deep acting $(\beta=0.2710, p<0.01)$ and genuine acting $(\beta=0.5262, p<0.01)$ positively, it affects surface acting $(\beta=-0.4808, p<0.01)$ negatively. This result shows that individuals with high cultural intelligence increase their ability to control their thoughts and feelings by empathizing in exhibiting the expected behaviors in a multicultural environment, and allow them to exhibit deep and genuine acting in a more sincere manner. Besides, results show that the individual's high cultural intelligence reduces the negative effect of surface acting, which does not give very successful results within the scope of emotional control. In this way, the negative situation that surface acting will cause on the individuals can be reduced. Very limited studies have examined the CQ and Emotional labor concepts. The research conducted by Chuapetcharasopon (2014) with 475 participants on the sub-dimensions of CQ and surface acting is in parallel with the results of our study. It was determined that some of the sub-dimensions of $C Q$ are directly and indirectly related to surface acting. Second study conducted by Salleh (2014) in the hospitality sector in Indonesia showed that there is a relationship between cultural intelligence and emotional labor. McCance's (2010) study conducted on 53 hotel employees in the hospitality industry revealed that CQ does not affect surface acting but deep acting. It is stated that emotional labor exhibition in the process of emotion management can produce different results due to demographic and sectoral differences (Erickson \& Stacey, 2013). In this context, the reason why the surface acting in McCance's (2010) study is statistically insignificant is thought to be due to the relatively small sample size (53) and hospitality sector. All these studies show that cultural intelligence has an effect on emotional labor and that the results of the study are parallel to the literature. Cultural intelligence enabled the decrease of the negative effects (surface acting) of the intense emotional labor experienced by NATO experts, who are in close contact with the public in the provision of services that the state is responsible for, in a multicultural environment. Also, CQ increased public servants' ability to offer their services more positively and genuinely (deep and genuine acting). The fact that NATO experts with high $\mathrm{CQ}$ exhibit the sincere and positive feelings that should be displayed as required by the task without the need to manipulate in a multicultural context, the negative situation (surface acting) that may occur decreases. This result of the study supports that $C Q$ can take place among the premises of emotional labor.

Another important result obtained in our research is that emotional labor dimensions (Surface acting $(\beta=0.2335, \mathrm{SE}=0.0299, \mathrm{GA}=[0.1796$ and 0.2984$])$ and genuine acting $(\beta=0.3686, \mathrm{SE}=0.0479, \mathrm{GA}=[0.2792$ and 0.4682]) have a partial mediating effect on increasing the job performance of CQ. This result of the study shows that employing individuals with high cultural intelligence, especially the public servants, increases job performance through exhibiting proper emotional labor strategy. By reducing surface acting, which is the negative situation experienced by a public employee who is expected to wear a tough and lawman mask during the execution of their duties, $C Q$ enables the public servants to feel their emotions more deeply and increase their job performance. This result is different from the findings of McCance's (2010) study. McCance (2010) conducted a study on 53 participants in the hospitality sector, and the findings revealed that surface and deep acting have no mediating roles on the effect of $C Q$ on job performance. McCance's sample consisted of 53 hotel employees, of which only 17 percent were employees such as the front desk who had direct contact with the customer. Also, only 27 percent of the customers per shift of 53 participants come from different cultures. Again, only $5.7 \%$ of the sample was made up of individuals outside of American culture (Other Asian, North Africa, Pacific Islander, Indian, and Pakistani). In the sample of our study, 
employees come together from different cultures under the NATO flag and serve individuals in the Afghan culture, which is very different from their own. It is considered that the difference experienced in the result is due to the relatively small size of McCance's sample and the sector difference (Erickson \& Stacey, 2013). Besides, it is considered that McCance's (2010) use of Baron and Kenny (1986) and Sobel's (1982) tests in determining the mediating role may have produced different results from the expected result due to the small size of the sample (53 people) and the asymmetrical distribution character of the indirect relationship (Hadi, Abdullah, \& Sentosa, 2016; Özdil \& Kutlu, 2019). Considering all these differences, it is evaluated that the study revealed a more inclusive result.

In the literature, studies on the concept of emotional labor are generally carried out between employees and customers who share the same culture. It is stated that there are gaps in the literature regarding the examination of emotional labor in a cultural context and the public sector (McCance, 2010; Van Gelderen, 2013; Guy, Newman \& Mastracci, 2014; Chuapetcharasopon, 2014; Salleh, 2014). It is considered that the study made significant contributions to the literature in terms of addressing the concept of emotional labor in a cultural context and examining cultural intelligence as one of emotional labor's premises. Also, it is considered that the negative impact of emotional labor could be decreased by employees with high cultural intelligence in future organizational environments where cultural diversity will increase (Caputo, Ayoko, Amoo \& Menke, 2019; Presbitero, 2019; Kong, Ma, Ji \& Li, 2020). It is considered that developing the abilities of the employees through the training planned in accordance with their cultural intelligence and deep acting levels will contribute positively to the performance of both the organization and the individual.

\subsection{Practical Implications}

The study offers potential practical implications for the training and recruitment process of service sector employees working in a multicultural environment. The study shows that in an environment where cultural difference and intense emotional labor are experienced, employees with high cultural intelligence reduce the negative impact of emotional labor on performance and contribute to the increase of individuals' job performance. This issue is also emphasized in other studies (McCance, 2010; Chuapetcharasopon, 2014; Salleh, 2014). High customer loyalty in the service sector is heavily affected by the emotional labor exhibition of employees (Kim et al., 2012). Besides, it is important to exhibit the behaviors that the customer expects and within the scope of the job requirements in the service sector (Guy, Newman \& Mastracci, 2014). In today's organizational environments where cultural diversity is increasing day by day, it is considered that the management's preference of individuals with high cultural intelligence in the process of recruitment is important in ensuring high performance, service quality and low emotional labor. It is important for the development of cultural intelligence that the training to be organized based on cross-cultural and experience (Lenartowicz, Johnson \& Konopaske, 2014). Providing employees with international experiences (Crowne, 2008; Wood \& Peters, 2014) and planning training programs for learning new languages (Planken, Van Hooft \& Korzilius, 2004; Barner-Rasmussen, Ehrnrooth, Koveshnikov \& Mäkelä, 2014) helps to develop their CQ skills. It is considered that developing the capacity of individuals to manage their behaviors with deep acting and cultural competence training programs will provide significant contributions to organizations (Grandey, 2003; Triandis, 2006; McCance \& Tunguz, 2010).

\subsection{Limitations and Avenues for Future Research}

As with every study, this study has some limitations. In the study, data has been obtained to cover military personnel and a cross-sectional study was conducted. The research model could be examined in larger samples that appeal to foreign customers, especially in the hospitality and service sector (flight attendants, nurses or front desk employees, etc.). Future research could analyze the model in the longitudinal study. Also, with different variables (intentions to quit, turnover, counterproductive work behaviors), the effect between cultural intelligence and emotional labor can be examined. 


\section{Disclosure Statements}

1. The authors of this article confirm that their work complies with the principles of research and publication ethics.

2. No potential conflict of interest was reported by the authors.

3. This article was screened for potential plagiarism using a plagiarism screening program.

\section{End Notes}

1. This study was created by developing the paper presented at the 28th National Management and Organization Congress.

\section{References}

Allport, G. W. (1937). Personality: A psychological interpretation. New York: Holt

Ang, S., Van Dyne, L., \& Koh, C. (2006). Personality correlates of the four-factor model of cultural intelligence. Group and Organization Management, 31(1), 100-123.

Ang, S., Van Dyne, L., Koh, C., Ng, K. Y., Templar, K. J., Tay, C., \& Chandrasekar, N. A. (2007). Cultural intelligence: Its measurement and effects on cultural judgement and decision making, cultural adaptation and task performance. Management and Organization Review, 3(03), 335-71.

Ang, S., \& Van Dyne, L. (2008). Conceptualization of cultural intelligence: Definition, distinctiveness, and nomological network. In S. Ang \& L. Van Dyne (Eds.), Handbook of cultural intelligence: Theory, measurement, and applications (3-15). New York, NY: Sharpe.

Ashforth, B. E., \& Humphrey, R. H. (1993). Emotional labor in service roles: The influence of identity. Academy of Management Review, 18(1), 88-115.

Baluku, M. M., Kikooma, J. F., Bantu, E., Onderi, P., \& Otto, K. (2019). Impact of personal cultural orientations and cultural intelligence on subjective success in self-employment in multi-ethnic societies. Journal of Global Entrepreneurship Research, 9(8).

Barakat, L. L., Lorenz, M. P., Ramsey, J. R., \& Cretoiu, S. L. (2016). Global managers: An analysis of the impact of cultural intelligence on job satisfaction and performance. International Journal of Emerging Markets, 10(4), 781-800.

Baron, R. M., \& Kenny, D. A. (1986). The moderator-mediator variable distinction in social psychological research: Conceptual, strategic, and statistical considerations. Journal of Personality and Social Psychology, 51(6), 1173.

Barner-Rasmussen, W., Ehrnrooth, M., Koveshnikov, A., \& Mäkelä, K. (2014). Cultural and language skills as resources for boundary spanning within the MNC. Journal of International Business Studies, 45, 886-905.

Barrera, J. C. (2010). An examination of cross-cultural competence in international business: The case of the subsidiaries. International Business \& Economics Research Journal, 9(1), 41-54.

Beğenirbaş, M., \& Çalışkan, A. (2014). Duygusal emeğin iş performansı ve işten ayrılma niyetine etkisinde kişilerarası çarpıklığın aracılık rolü. Business and Economics Research Journal, 5(2), 109-127.

Bharwani, S., \& Jauhari, V. (2013). An exploratory study of competencies required to co-create memorable customer experiences in the hospitality industry. International Journal of Contemporary Hospitality Management, 25(6), 823-843.

Bollen, K. A., \& Stine, R. (1990). Direct and indirect effects: Classical and bootstrap estimates of variability. Sociological Methodology, 20, 115-140.

Brotheridge, C. M., \& Grandey, A. A. (2002). Emotional labor and burnout: Comparing two perspectives of "people work". Journal of Vocational Behavior, 60(1), 17-39.

Buckner, J. E. V. (2012). Emotional labor and authentic leadership. Doctoral Dissertation, Lousiana Tech University, USA.

Bücker, J. L. E., Furrer, O., Poutsma, E., \& Buyens, D. (2014). The impact of cultural intelligence on communication effectiveness, job satisfaction and anxiety for Chinese host country managers working for foreign multinationals. The International Journal of Human Resource Management, 25(14), 2068-2087.

Caputo, A., Ayoko, O. B., Amoo, N., \& Menke, C. (2019). The relationship between cultural values, cultural intelligence and negotiation styles. Journal of Business Research, 99, 23-36.

Cervone, D., \& Pervin, L. A. (2008). Personality: Theory and research (10th Ed.). Hoboken, NJ: John Wiley \& Sons, Inc. 
Chi, N. W., \& Grandey, A. A. (2019). Emotional labor predicts service performance depending on activation and inhibition regulatory fit. Journal of Management, 45, 673-700.

Chu, K. H. L., \& Murrmann, S. K. (2006). Development and validation of the hospitality emotional labor scale. Tourism Management, 27, 1181-1191.

Chuapetcharasopon, P. (2014). Emotional labour in the global context: The roles of intercultural and intracultural service encounters, intergroup anxiety, and cultural intelligence on surface acting. Doctoral Dissertation, University of Waterloo, Waterloo, Ontario, Canada

Crowne, K. A. (2008). What leads to cultural intelligence? Business Horizons, 51(5), 391-399.

Çalışkan, S. C., Ünal, Z. M., Kalafatoğlu, Y., Üçler, Ç., \& Akün, F. A. (2015). Yöneticilerin algılanan kültürel zekâsı, çalışanın farklılık iklimi algısı, gelişime açıklık ve örgütsel sinizm etkileşimi üzerine turizm sektöründe bir araştırma. Iş ve insan Dergisi, 2(1), 1-11.

Dahling, J. J., \& Johnson, H. M. (2013). Motivation, Fit, Confidence, and Skills: How Do Individual Differences Influence Emotional Labor? In A. Grandey, J. Diefendorff \& D. Rupp (Eds.), Emotional labor in the 21st century: Diverse perspectives on emotion regulation at work (57-78). London and Newyork: Routledge Taylor and Francis Group.

Daus, C. S., \& Brown, S. (2012). The emotion work of police. In H. Zerbe (Eds.), Experiencing and managing emotions in the workplace. Bingley, UK: Emerald Publishing Limited.

Depaula, P. D., Azzollini, S. C., Cosentino, A. C., \& Castillo, S. E. (2016). Personality, character strengths and cultural intelligence: "Extraversion" or "openness" as further factors associated to the cultural skills. Avances en Psicología Latinoamericana, 34(2), 415-436.

Diefendorff, J. M., Croyle, M. H., \& Gosserand, R. H. (2005). The dimensionality and antecedents of emotional labor strategies. Journal of Vocational Behavior, 66(2), 339-357.

Elenkov, D. S., \& Manev, I. M. (2009). Senior expatriate leadership's effects on innovation and the role of cultural intelligence. Journal of World Business, 44(4), 357-369.

Erickson, R. J., \& Stacey, C. L. (2013). Attending to mind and body: Engaging the complexity of emotion practice among caring professionals. In A. A. Grandey, J. M. Diefendorff \& D. E. Rupp (Eds.), Emotional labor in the 21st century: Diverse perspectives on emotion regulation at work (pp. 175-196). New York, NY: Psychology Press/Routledge.

Eskandarpur, B., Nazari, G., Vejdan, R., \& Tohidi, A. (2013). The study of the relationship between cultural intelligence and organizational commitment. Journal of Basic and Applied Scientific Research, 3(1), 823-829.

Fang, F., Schei, V., \& Selart, M. (2018). Hype or hope? A new look at the research on cultural intelligence. International Journal of Intercultural Relations, 66, 148-171.

Fritz, M., \& MacKinnon, D. (2007). Required sample size to detect the mediated effect. Psychological Science, 18(3), 233239.

Goldberg, L. S., \& Grandey, A. A. (2007). Display rules versus display autonomy: Emotion regulation, emotional exhaustion, and task performance in a call center simulation. Journal of Occupational Health Psychology, 12, 301318.

Goodwin, R. E., Groth, M., \& Frenkel, S. J. (2011). Relationships between emotional labor, job performance, and turnover. Journal of Vocational Behavior, 79, 538-548.

Grandey, A. A. (2003). When the show must go on: Surface acting and deep acting as determinants of emotional exhaustion and peer-rated service delivery. Academy of Management Journal, 46, 86-96.

Grandey, A. A. (2000). Emotional regulation in the workplace: A new way to conceptualize emotional labor. Journal of Occupational Health Psychology, 5(1), 95-110.

Grandey, A. A., Fisk, G. M., Mattila, A. S., Jansen, K. J., \& Sideman, L. A. (2005). Is "service with a smile" enough? Authenticity of positive displays during service encounters. Organizational Behavior and Human Decision Processes, 96, 38-55.

Gross, J. J. (1998). Antecedent and response focused emotion regulation: Divergent consequences for experience, expression, and physiology. Journal of Personality and Social Psychology, 74(1), 224-237.

Groves, K. S., \& Feyerherm, A. E. (2011). Leader cultural intelligence in context: Testing the moderating effects of team cultural diversity on leader and team performance. Group and Organization Management, 36(5), 535-566.

Guy, M. E., Newman, M. A., Mastracci, S. H. (2014). Emotional labor: Putting the service in public service. London and Newyork: Routledge Taylor and Francis Group. 
Hadi, N., Abdullah, N., \& Sentosa, I. (2016). Making sense of mediating analysis: A marketing perspective. Review of Integrative Business \& Economics Research, 5, 62-76.

Hair Jr, J. F., Hult, G. T. M., Ringle, C., \& Sarstedt, M. (2014). A primer on partial least squares structural equation modeling (PLS-SEM). CA: Thousands Oaks, Sage.

Hair Jr, J. F., Sarstedt, M., Ringle, C. M., \& Gudergan, S. P. (2017). Advanced issues in partial least squares structural equation modeling. SAGE publications.

Harrison, N. (2012). Investigating the impact of personality and early life experiences on intercultural interaction in internationalised universities. International Journal of Intercultural Relations, 36(2), 224-237.

Hayes, A. F. (2013). Methodology in the social sciences. Introduction to mediation, moderation, and conditional process analysis: A regression-based approach. New York: Guilford Press.

Hayes, A. F., Montoya, A. K., \& Rockwood, N. J. (2017). The analysis of mechanisms and their contingencies: PROCESS versus structural equation modeling. Australasian Marketing Journal (AMJ), 25(1), 76-81.

Hochschild, A. R. (1979). Emotion work, feeling rules, and social structure. American Journal of Sociology, 85(3), 551575.

Hochschild, A. R. (1983). The managed heart: Commercialization of human feeling. Berkeley: University of California Press.

Jyoti, J., \& Kour, S. (2015). Assessing the cultural intelligence and task performance equation. Cross Cultural Management: An International Journal, 22(2), 236-258.

J-MHAT 7 Report (2011). Joint Mental Health Advisory Team 7 (J-MHAT 7) Operation Enduring Freedom 2010 Afghanistan. Avaliable at: https://apps.dtic.mil/dtic/tr/fulltext/u2/a543 997.pdf (Access Date: 10.11.2020).

Kim, T., Yoo, J., Lee, G., \& Kim, J. (2012). Emotional intelligence and emotional labor acting strategies among frontline hotel employees. International Journal of Contemporary Hospitality Management, 24, 1029-1046.

Kirkman, B. L., \& Rosen, B. (1999). Beyond self-management: Antecedents and consequences of team empowerment. Academy of Management Journal, 42(1), 58-74.

Kline, R. B. (2005). Methodology in the social sciences. Principles and practice of structural equation modeling (2nd ed.). Guilford Press.

Kong, L. L., Ma, Z. Q., Ji, S. H., \& Li, J. (2020). The mediating effect of empathy on the relationship between cultural intelligence and intercultural adaptation in intercultural service encounters. The Journal of Asian Finance, Economics and Business, 7(2), 169-180.

Kour, S., \& Sharma, S. (2017). Examining the impact of personality traits on cultural intelligence. Pacific Business Review International, 10(6), 77-84.

Kurpis, L. H., \& Hunter, J. (2017). Developing students' cultural intelligence through an experiential learning activity: A cross-cultural consumer behavior interview. Journal of Marketing Education, 39(1), 30-46.

Lee, H. E. (2015). Does a server's attentiveness matter? Understanding intercultural service encounters in restaurants. International Journal of Hospitality Management, 50, 134-144.

Lenartowicz, T., Johnson, J. P., \& Konopaske, R. (2014). The application of learning theories to improve cross-cultural training programs in MNCs. International Journal of Human Resource Management, 25, 1697-1719.

Li, M., Mobley, W. H., \& Kelly, A. (2013). When do global leaders learn best to develop cultural intelligence? An investigation of the moderating role of experiential learning style. Academy of Management Learning \& Education, 12(1), 32-50.

Livermore, D. (2011). The cultural intelligence difference master the one skill you can't do without in today's global economy. New York: Amacom.

Lorenz, M., Ramsey, J., \& Richey, R. (2018). Expatriates' international opportunity recognition and innovativeness: The role of metacognitive and cognitive cultural intelligence. Journal of World Business, 53, 222-236.

Lustig, M. W., \& Koester, J. (2006). Intercultural competence: Interpersonal communication across cultures (5th ed.). Boston, MA: Pearson.

McCance, A. S. (2010). Emotional labor in intercultural service encounters: An experience sampling study. Doctoral Dissertation, University of Waterloo, Ontario, Canada.

McCance, A. S., \& Tunguz, S. (2010). Emotion regulation training reaps psychological and organizational rewards. Paper presented at the 25th annual meeting of the Society for Industrial and Organizational Psychology, Atlanta, GA. 
MacKenzie, S. B., Podsakoff, P. M., \& Podsakoff, N. P. (2011). Construct measurement and validation procedures in MIS and behavioral research: Integrating new and existing techniques. MIS Quarterly, 35(2), 293-334.

Mesquita, B., \& Albert, D. (2007). The cultural regulation of emotions. In J. J. Gross (Ed.), Handbook of emotion regulation (pp. 486-503). The Guilford Press.

Mesquita, B., \& Delvaux, E. (2013). A cultural perspective on emotion labor. In A. Grandey, J. Diefendorff, \& D. Rupp (Eds.), Emotional labor in the 21st century: Diverse perspectives on emotion regulation at work (pp. 251-272) London and Newyork: Routledge Taylor and Francis Group

Morris, J. A., \& Feldman, D. C. (1996). The dimensions, antecedents, and consequences of emotional labor. Academy of Management Review, 21(4), 986-1010.

NATO and Afganistan. (2020). Avaliable at https://www.nato.int/cps/en/natohq/topics_8189 (Access Date: 10.11.2020).

Ng, Y., \& Earley, C. 2006. Culture intelligence: Old constructs, new frontiers. Group and Organization Management, 31(1), 4.

O’Dowd, R. (2018). Intercultural communicative competence and technology. Wiley, Hoboken, NJ.

Ott, D. L., \& Michailova, S. (2016). Cultural intelligence: A review and new research avenues. International Journal of Management Reviews, 20(1), 99-119.

Özdil, S. O., \& Kutlu, O. (2019). Investigation of the mediator variable effect using BK, Sobel and Bootstrap methods (Mathematical Literacy Case). International Journal of Progressive Education, 15(2), 30-43.

Pardo, A., \& Roman, M. (2013). Reflections on the Baron and Kenny model of statistical mediation. Anales de psicologia, 29(2), 614-623.

Parker, B. (2005). Introduction to globalization and business: Relationships and responsibilities. London: SAGE.

Pekerti, A. A., \& Arli, D. (2017). Do cultural and generational cohorts matter to ideologies and consumer ethics? A comparative study of Australians, Indonesians, and Indonesian migrants in Australia. Journal of Business Ethics, 143(2), 387-404.

Peterson, B. (2004). Cultural intelligence: A guide to working with people from other cultures. Yarmouth: Intercultural Press.

Planken, B., Van Hooft, A., \& Korzilius, H. (2004). Promoting intercultural communicative competence through foreign language courses. Business Communication Quarterly, 67(3), 308-315.

Prati, L. M. (2004). Emotional intelligence as a facilitator of the emotional labor process. Doctoral Dissertation, The Florida State University, Tallahassee.

Preacher, K. J., \& Hayes, A. F. (2004). SPSS and SAS procedures for estimating indirect effects in simple mediation models. Behavior Research Methods, Instruments, and Computers, 36, 717-731.

Preacher, K. J., \& Hayes, A. (2008). Asymptotic and resampling strategies for assessing and comparing indirect effects in multiple mediator models. Behavior Research Methods, 40(3), 879-889.

Presbitero, A. (2019). Foreign language skill, anxiety, cultural intelligence and individual task performance in global virtual teams: A cognitive perspective. Journal of International Management, 100729. doi:10.1016/j.intman.2019.100729

Richards, J. M., \& Gross, J. J. (1999). Composure at any cost? The cognitive consequences of emotion suppression. Personality and Social Psychology Bulletin, 25, 1033-1044.

Rose, R. C., Ramalu, S. S., Uli, J., \& Kumar, N. (2010). Expatriate performance in international assignments: The role of cultural intelligence as dynamic intercultural competency. International Journal of Business and Management, 5(8), 76-85.

Rupp, D. E., McCance, A. S., Spencer, S., \& Sonntag, K. (2008). Customer (in) justice and emotional labor: The role of perspective taking, anger, and emotional regulation. Journal of Management, 34(5), 903-924.

Salleh, N. (2014). Emotional labor in the cross-cultural setting. Doctoral Dissertation, Institut Teknologi Brunei (ITB), Brunei Darussalam.

Schwarzenthal, M., Juang, L. P., Schachner, M. K., van de Vijver, F. J. R., \& Handrick, A. (2017). From tolerance to understanding: Exploring the development of intercultural competence in multiethnic contexts from early to late adolescence. Journal of Community and Applied Social Psychology, 27(5), 388-399.

Schaible, L. M., \& Six, M., 2016. Emotional strategies of police and their varying consequences for burnout. Police Quarterly, 19(1), 3-31. 
Shaffer, M. A., Harrison, D. A., Gregersen, H., Black, J. S., \& Ferdandi, L. A. (2006). You can take it with you: Individual differences and expatriate effectiveness. Journal of Applied Psychology, 91(1), 109-125.

Shrout, P. E., \& Bolger, N. (2002). Mediation in experimental and nonexperimental studies: New procedures and recommendations. Psychological Methods, 7, 422-445

Stanley, E. A., \& Larsen, K. L. (2019). Difficulties with emotion regulation in the contemporary U.S. armed forces: Structural contributors and potential solutions. Armed Forces \& Society, 0095327X1984801. doi:10.1177/0095327x19848018

Sigler, T. H., \& Pearson, C. M. (2000). Creating an empowering culture: examining the relationship between organizational culture and perceptions of empowerment. Journal of Quality Management, 5, 27-52.

Sürücü, L., \& Sürücü, D. (2020) Organizational Culture and Demographic Characteristics of Employees, Journal of Business Research-Turk, 12(2), 1046-1057.

Sürücü, L., \& Maslakçı, A. (2020). Validity and reliability in quantitative research. Business \& Management Studies: An International Journal, 8(3), 2694-2726.

Şahin, F. (2011). Liderin kültürel zekâsının astların örgütsel vatandaşlık davranışı ile iş doyumu üzerine etkisi. Savunma Bilimleri Dergisi, 10(2), 80-104.

Tay, C., Westman, M., \& Chia, A. (2008). Antecedents and consequences of cultural intelligence among short-term business travelers. In S. Ang \& L. Van Dyne (Eds.). Handbook of cultural intelligence: Theory, measurement, and applications (pp. 126-144). New York: M. E. Sharpe.

Telli, A., \& Zehir, C. (2016). Examining the effect of cultural differences measuring with cultural intelligence scale (cqs) on employee's job satisfaction in multi-cultural companies. Research Journal of Business and Management, 3(4), 267-267.

Teng, H. Y. (2019). Job crafting and customer service behaviors in the hospitality industry: Mediating effect of job passion. International Journal of Hospitality Management, 81, 34-42.

Tice, D. M., \& Bratslavsky, E. (2000). Given in to feel good: The place of emotion regulation in the context of general self-control. Psychological Inquiry, 11(3), 149-159.

Totterdell, P., \& Holman, D. (2003). Emotion regulation in customer service roles: Testing a model of emotional labor. Journal of Occupational Health Psychology, 8, 55-73.

Triandis, H. C. (2006). Cultural intelligence in organisations. Group and Organisations Management, 31(1), 20-26.

Van Dyne, L., Ang, S., \& Koh, C. (2008). Development and validation of the CQS: The Cultural Intelligence Scale. In S. Ang \& L. Van Dyne (Eds.), Handbook on cultural intelligence: Theory, measurement and applications (pp. 16-38). NewYork, NY: M. E. Sharpe.

Van Gelderen, B. (2013). At the heart of policing emotional labor among police officers. Doctoral Dissertation, Erasmus Universiteit Rotterdam, Nederland.

Wang, M. (2016). Effects of expatriates' cultural intelligence on cross-cultural adjustment and job performance. Revista de Cercetare si Interventie Sociala, 55, 231-243.

Wharton, A. S., \& Erickson, R. I. (1993). Managing emotions on the job and at home: Understanding the consequences of multiple emotional roles. Academy of Management Review, 18(3), 457-486.

White, R. D. (1999). Managing the diverse organization: The imperative for a new multicultural paradigm. Public Administration \& Management: An Interactive Journal, 4(4), 469-493.

Wood, E. D., \& St. Peters, H. Y. (2014). Short-term cross-cultural study tours: Impact on cultural intelligence. International Journal of Human Resource Management, 25, 558-570.

Xu, X. J., \& Chen, X. P. (2017). Unlocking expatriates job creativity: The role of cultural learning, and metacognitive and motivational cultural intelligence. Management and Organization Review, 13(4), 767-794.

Yıldız, H. (2016). The relationship among cultural intelligence entrepreneurship orientation and innovative behaviors. Eurasian Academy of Sciences Eurasian Business and Economics Journal, 1, 90-101. 